Proceedings

\title{
Formulation and In Vitro Comparison Study between Lipid-Based and Polymeric-Based Nanoparticles for Nose-to-Brain Delivery of a Model Drug for Alzheimer's Disease ${ }^{+}$
}

\author{
Hussein Akel and Ildikó Csóka *
}

Citation: Akel, H.; Csóka, I.

Formulation and In Vitro

Comparison Study between

Lipid-Based and Polymeric-Based

Nanoparticles for Nose-to-Brain

Delivery of a Model Drug for

Alzheimer's Disease. Proceedings

2021, 78, 51. https://doi.org/10.3390/

IECP2020-08680

Published: 1 December 2020

Publisher's Note: MDPI stays neutral with regard to jurisdictional claims in published maps and institutional affiliations.

Copyright: $\odot 2020$ by the authors. Licensee MDPI, Basel, Switzerland. This article is an open access article distributed under the terms and conditions of the Creative Commons Attribution (CC BY) license (http://creativecommons.org/licenses/by/4.0/).
Institute of Pharmaceutical Technology and Regulatory Affairs, Faculty of Pharmacy, University of Szeged, Eötvös str. 6., H-6720 Szeged, Hungary; hussein.akel@hotmail.com

* Correspondence: csoka.ildiko@szte.hu; Tel.: +36-62-546116

+ Presented at the 1st International Electronic Conference on Pharmaceutics, 1-15 December 2020; Available online: https://iecp2020.sciforum.net/.

\begin{abstract}
Certain challenges like the presence of highly complex structure (blood-brain barrier (BBB)), P-glycoprotein efflux, and the particular enzymatic activity stand in the way of the successful delivery of the drug moieties to the brain and make them fruitless. Many efforts have been conducted to overcome the previous. Direct delivery of drugs to the brain after the intranasal application is one of those strategies since it holds a great hope to raise the chances of drug moieties to the brain. Nanoparticles could be the potential to improve nose-to-brain drug delivery since they are able to protect the encapsulated drugs from biological and/or chemical degradation and increase their penetration across biological barriers. Based on the fact that neuroinflammation is associated with neuron death and neurodegenerative diseases like Alzheimer's, nonsteroidal anti-inflammatory drugs (NSAIDs) might play a positive role in the disease. The present study aimed to employ the $\mathrm{QbD}$ approach for the first time in optimizing polymeric and lipid-based nanoparticles for the nose-to-brain delivery of Meloxicam (MEL), and to perform a comparison between the pure drug and the formulated nanosystems regarding dissolution profiles, permeability, and mucoadhesiveness.
\end{abstract}

Keywords: nose to brain; polymeric nanoparticles; solid lipid nanoparticles; solid lipid nanoparticles; dissolution profiles; permeability; mucoadhesiveness

\section{Introduction}

The blood-brain barrier (BBB) presence forms the major drawback to the successful delivery of the brain targeting moieties to their active site. On the other hand, the P-glycoprotein efflux supports the preventing role of the BBB by transporting the particles out of the CNS. However, this physiological protective barrier is considered a fundamental challenge to the pharmaceutical fraternity, with a need to circumvent it to deliver drugs to the brain in various CNS disorders [1-3].

Nose to brain delivery route holds a great promise to overcome the BBB since it transports the drug directly to the brain along the olfactory and trigeminal nerve pathways. These nerve pathways initiate the nasal cavity at the olfactory neuroepithelium and terminate in the brain [4].

Several clinical studies concluded that long-term use of nonsteroidal anti-inflammatory drugs (NSAIDs) might protect against the onset of Alzheimer's disease (AD) [5]. Among those, meloxicam exerts its pharmacological properties by inhibiting the enzy- 
matic activity of cyclooxygenase-2 (COX-2) [6], which linked with a neuroprotective action in Alzheimer's disease [7-10]. Unfortunately, meloxicam is a lipophilic drug with high potency and poor water solubility [11], which decreases its bioavailability when it is applied following the routine routes of administration.

The strategy of designing drugs in an encapsulated form of nanoparticles (NPs) to target the olfactory epithelium could potentially improve the direct CNS delivery of the drugs including biologics following the intranasal application [2]. Solid lipid NPs (SLNs) and PLGA NPs are preferable candidates for this purpose owing to the desired characteristics they have, including: increasing in the nasal permeability, controlling the drug release [12], protecting the encapsulated drug from biological and/or chemical degradation enhancing the drug retention time in the nasal mucosa due to their good mucoadhesion [13,14].

Since there are many factors that can affect the characteristics and properties of the previously mentioned nanosystems, the application of $\mathrm{QbD}$ approach presents a logical strategy that saves time, costs, and efforts when developing complex systems such as the nanosystems [14]. Starting by the definition of the quality target product profile (QTPP), then the critical process parameters (CPPs) and critical material attributes (CMAs) that can highly affect the critical quality attributes (CQAs) of the product [15].

In the present research, two types of nanoparticles were prepared following a $\mathrm{QbD}$ approach. Physical, chemical, and morphological characterization were conducted. The following step was to evaluate their in vitro behavior regarding release profile, permeation and mucoadhesion properties. Correspondingly, a profound comparison was performed followed by the selection of the optimized nanocarrier system to be a successful candidate for nose-to-brain delivery of anti-AD drug formulation.

\section{Experiments}

\subsection{Materials}

Cholesterol was purchased from MOLAR Chemicals (Budapest, Hungary), while Phosphatidylcholine, Pluronic F68, Tween80, and PVA were supplied by Sigma Aldrich (Steinheim, Germany). Meloxicam was obtained from Egis Pharmaceuticals Ltd. (Budapest, Hungary). Trehalose dihydrate, Mannitol, as well as all the organic solvents (analytical grade) were purchased from Merck (Darmstadt, Germany).

\subsection{Preparation of MEL-Loaded NPS}

\subsubsection{MEL-Loaded SLNs}

MEL-loaded SLNs were prepared following a modified double emulsion (W1/O/W2) solvent evaporation (DESE) technique [16]. MEL was dissolved in $0.1 \mathrm{M} \mathrm{NaOH}$ solution formulating the W1 Phase. The oily phase was prepared by dissolving phosphatidylcholine in cyclohexane. The primary emulsion was formed by adding the W1 phase dropwise into the organic phase using a homogenizing mixer (Hielscher, Germany) ( 0.5 cycles and $75 \%$ amplitude) for $1 \mathrm{~min}$. The resultant nanoemulsion was then added dropwise into poloxamer aqueous solution using the homogenizing mixer $(0.5$ cycles and $75 \%$ amplitude) for $1 \mathrm{~min}$. The final mixture was left then to stir overnight using a magnetic stirrer to allow the evaporation of the organic solvent and thus formulation of the SLNs.

\subsubsection{MEL-Loaded PLGA NPs}

MEL-loaded PLGA NPs were prepared using another DESE technique [17]. First, the formation of a primary W1/O emulsion took place, where the aqueous solution of the MEL was added to the PLGA solution in ethyl acetate upon sonication in an ice bath. This was followed by dispersing the primary emulsion in an external aqueous solution of Poloxamer 188, with the presence of sonication in an ice bath. Finally, the organic solvent evaporation overnight resulted in the formation of MEL-NPs. 
Both the NPs were harvested by centrifugation at $16,000 \times g$ for $1 \mathrm{~h}$ at $10^{\circ} \mathrm{C}$ (Sigma, Neustadt, Germany) and washed three times with deionized water to remove unentrapped drug, surfactants and remaining organic solvent.

The NPs were then resuspended in $2 \mathrm{~mL}$ of $10 \%(w / v)$ trehalose aqueous solution, frozen at $-20{ }^{\circ} \mathrm{C}$, and were finally freeze-dried (Christ, Germany) at $-40{ }^{\circ} \mathrm{C}$ for $72 \mathrm{~h}$.

\subsection{Characterization of NPS}

\subsubsection{Mean Particle Diameter, Size Distribution and Zeta Potential}

The average hydrodynamic diameter (Z-average), polydispersity index (PDI), and surface charge (zeta potential) of the NPs were analyzed in folded capillary cells, using Malvern nano ZS instrument (Malvern Instruments, Worcestershire, UK).

\subsubsection{Encapsulation Efficacy and Drug Load}

The obtained NPs were separated from the preparation medium by centrifugation and washed three times, and each time was followed by centrifugation to obtain NPs pellets. Meloxicam then was extracted using chloroform. The mixture was moved to a separatory funnel, and the aqueous phase was withdrawn to determine its drug content by HPLC, and the EE and DL were calculated according to the following equations:

$$
\begin{aligned}
& E E=\frac{\text { The calculated amount of MEL encapsulated in the freeze-dried SLNs }}{\text { Total amount of MEL used in the preparation }} \times 100 \\
& D L=\frac{\text { The calculated amount of MEL encapsulated in the freeze-dried SLNs }}{\text { The weight of the freeze-dried SLNs }} \times 100
\end{aligned}
$$

\subsubsection{Scanning Electron Microscopy (SEM)}

The morphological appearance of the NPs was investigated using scanning electron microscopy (SEM) (Hitachi S4700, Hitachi Scientific Ltd., Tokyo, Japan) at $10 \mathrm{kV}$.

\subsubsection{Fourier-Transform Infrared Spectroscopy (FTIR)}

The chemical interactions between the drug and excipients were analyzed by a Thermo Nicolet AVATAR FTIR spectrometer (Thermo-Fisher, Waltham, MA, USA).

\subsubsection{X-ray Powder Diffraction XRPD}

The X-ray powder diffractograms of phosphatidylcholine, PLGA, poloxamer, SLNs, and PLGA NPs were obtained in the angular range of $3-40^{\circ} 2 \theta$ at a step time of $0.1 \mathrm{~s}$ and a step size of $0.007^{\circ}$ at ambient temperature. Monochromatic $\mathrm{CuK} \alpha 1$ radiation (with $\lambda=1.5406 \AA$ ) at $40 \mathrm{kV}$ and $40 \mathrm{~mA}$ was used as the $\mathrm{X}$-ray source. The same was repeated with the polymeric NPs.

\subsection{In vitro evaluation of the NPs:}

\subsubsection{Dissolution Test}

Dissolution of meloxicam and the drug release from MEL-NPs was determined using a dialysis bag diffusion technique using a dialysis membrane [18-20]. The samples were analyzed spectrophotometrically at $\lambda$ max of $346 \mathrm{~nm}$ (Jasco V730 UV-VIS spectrophotometer (ABL\&E-JASCO Ltd., Budapest, Hungary).

\subsubsection{Mucoadhesiveness Test}

Mucoadhesion was determined following the direct method (turbidimetric method) as following: briefly, the mucin was in PBS $6.4\left(0.5 \mathrm{mg} \mathrm{mL}^{-1}\right)$, and the NPs were mixed and incubated at $37^{\circ} \mathrm{C}$ with continuous stirring with predetermined times of $1,2,3$, and $4 \mathrm{~h}[21,22]$. 


\subsubsection{Permeation Test}

In vitro permeation of the prepared NPs was investigated using side-by-side type apparatus as follows: accurate weights of MEL and MEL NPs equivalent to $1 \mathrm{mg}$ of MEL were suspended in $9 \mathrm{~mL}$ of simulated nasal electrolyte solution (SNES), then placed in the donor chamber. On the other hand, $9 \mathrm{~mL}$ of $\mathrm{pH} 7.40$ phosphate buffer was placed in the acceptor chamber. A semipermeable cellulose membrane, previously impregnated in isopropyl myristate for $1 \mathrm{~h}$, was placed between the two chambers as membrane to imitating the presence of the nasal mucosa. The permeation test was conducted for $1 \mathrm{~h} \mathrm{comparing}$ pure MEL, optimized SLNsandPLGA NPs.

\section{Results}

\subsection{Risk Assessment}

Risk assessment was conducted to rank and prioritize the factors with the highest impact on product quality. The first step of the QbD-based risk assessment study was to set the QTPP encompassing the desired quality attributes in MEL-NPs, followed by the selection of CPPs and CMAs. The previous is summarized and ranked as in Figure 1

\begin{tabular}{|c|c|c|c|c|c|c|c|}
\hline $\begin{array}{ll}\text { CQAs } & \text { QTPPs } \\
\end{array}$ & $\begin{array}{l}\text { Therapeutic } \\
\text { indication }\end{array}$ & $\begin{array}{c}\text { Nasal } \\
\text { Administration }\end{array}$ & $\begin{array}{c}\text { Dosage } \\
\text { form }\end{array}$ & $\begin{array}{l}\text { Nasal mucosa } \\
\text { accessability }\end{array}$ & $\begin{array}{l}\text { Absorption } \\
\text { feature }\end{array}$ & $\begin{array}{l}\text { Targeting the } \\
\text { CNS }\end{array}$ & Severity score \% \\
\hline Size & M & $\mathrm{H}$ & $\mathrm{L}$ & $\mathrm{H}$ & $\mathrm{H}$ & $\mathrm{H}$ & 22.65 \\
\hline $\mathrm{ZP}$ & M & $\mathrm{H}$ & $\mathrm{L}$ & M & M & $\mathrm{H}$ & 18.26 \\
\hline $\mathrm{EE}$ & $\mathrm{H}$ & $\mathrm{H}$ & $\mathrm{L}$ & $\mathrm{L}$ & $\mathrm{H}$ & $\mathrm{H}$ & 12.36 \\
\hline Mucoadhesion & $\mathrm{H}$ & $\mathrm{H}$ & $\mathrm{H}$ & $\mathrm{H}$ & $\mathrm{L}$ & $\mathrm{H}$ & 9.47 \\
\hline Dissolution profile & $\mathrm{H}$ & $\mathrm{H}$ & $\mathrm{L}$ & $\mathrm{H}$ & $\mathrm{H}$ & $\mathrm{H}$ & 8.12 \\
\hline permeability & $\mathrm{H}$ & $\mathrm{H}$ & $\mathrm{H}$ & $\mathrm{H}$ & $\mathrm{H}$ & $\mathrm{H}$ & 6.38 \\
\hline
\end{tabular}

\begin{tabular}{|c|c|c|c|c|c|c|c|c|c|c|c|c|c|c|c|}
\hline CMAs & Size & $\mathrm{ZP}$ & $\mathrm{EE}$ & $\begin{array}{l}\text { Dissolution } \\
\text { profile }\end{array}$ & Mucoadhesion & Permeability & $\begin{array}{l}\text { Severity } \\
\text { score \% }\end{array}$ & CMAs & Size & ZP & EE & $\begin{array}{c}\text { Dissolution } \\
\text { profile }\end{array}$ & Mucoadhesion & Permeability & $\begin{array}{l}\text { Severity } \\
\text { score } \%\end{array}$ \\
\hline $\begin{array}{l}\text { Surfactant } \\
\text { type }\end{array}$ & H & $\mathrm{H}$ & $\mathrm{H}$ & $\mathrm{H}$ & $\mathrm{H}$ & $\mathrm{H}$ & 47.26 & sonication speed & $\mathrm{H}$ & $\mathrm{H}$ & $\mathrm{L}$ & $\mathrm{M}$ & $\mathrm{L}$ & L & 39.11 \\
\hline $\begin{array}{l}\text { Surfactant } \\
\text { concentration }\end{array}$ & $\mathrm{H}$ & H & $\mathrm{H}$ & $\mathrm{H}$ & $\mathrm{H}$ & $\mathrm{H}$ & 20.74 & sonication time & II & $\mathrm{H}$ & H & H & $\mathrm{L}$ & L & 17.97 \\
\hline $\begin{array}{l}\text { Lipid/polymer } \\
\text { type }\end{array}$ & M & H & M & $\mathrm{H}$ & $\mathrm{H}$ & M & 17.32 & $\begin{array}{l}\text { Solvent } \\
\text { evaporation } \\
\text { time }\end{array}$ & $\mathrm{L}$ & $\mathrm{L}$ & $\mathrm{L}$ & M & $\mathrm{L}$ & $\mathrm{L}$ & 13.61 \\
\hline $\begin{array}{l}\text { Lipid/polymer } \\
\text { concentration }\end{array}$ & $M$ & $\mathrm{H}$ & M & M & $\mathrm{H}$ & $\mathrm{M}$ & 12.79 & $\begin{array}{l}\text { Solvent } \\
\text { evaporation } \\
\text { speed }\end{array}$ & L & $\mathrm{L}$ & M & M & $\mathrm{L}$ & L & 8.08 \\
\hline
\end{tabular}

Figure 1. Risk assessment of the MEL-loaded nanoparticles showing the relationship between QTPPs-CQAs, CQAsCMAs, CQAs-CPPs with the calculated severity scores in decreasing order of risks. Abbreviations: QTPP - quality target product profile; $\mathrm{CQA}$ - critical quality attributes; $\mathrm{CMAs}-$ critical material attributes; $\mathrm{CPP}$-critical process parameters; CNS - central nervous system; ZP - zeta potential; EE - encapsulation efficacy; L-low; $\mathrm{M}$ - medium; $\mathrm{H}$-high.

\subsection{Morphology, Size, ZP and EE}

The resulted NPs were smooth and spherical in shape as shown in Figure 2. 


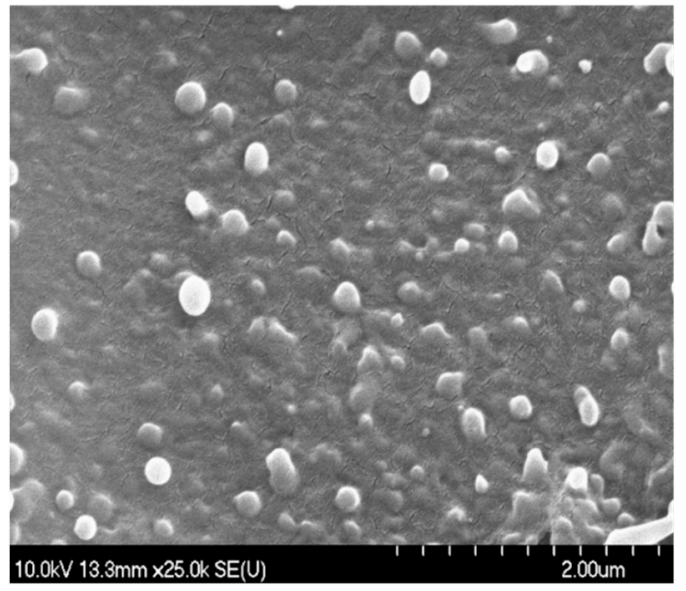

(A)

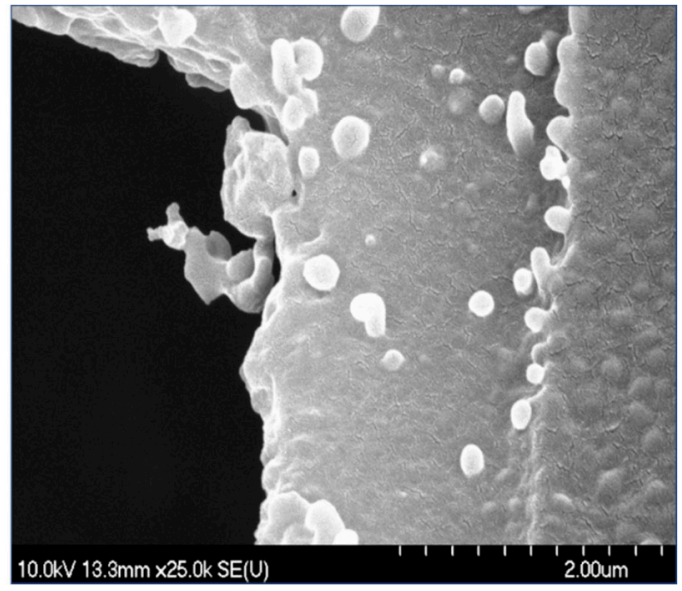

(B)

Figure 2. SEM photos for the obtained nanoparticles, where (A): SLNs, (B): PLGA NPs. Abbreviation: SEM-scanning electron microscope; SLNs - solid lipid nanoparticles; PLGA NPs - Poly (Llactide co-glycolide acid nanoparticles.

After that the Particle size, ZP, and EE were measured as the major physical characteristics and the result are listed in the following table, Table 1.

Table 1. Size, zeta potential and encapsulation efficacy of the optimized nanoformulations.

\begin{tabular}{cccc}
\hline Sample & Particle Size $(\mathbf{n m})$ & ZP & EE\% \\
\hline PLGA NPs & $142.02 \pm 12.83$ & $-16.2 \pm 1.81$ & $87.26 \pm 3.16 \%$ \\
\hline SLNs & $94.76 \pm 7.41$ & $-43.65 \pm 1.47$ & $72.23 \pm 2.84 \%$ \\
\hline
\end{tabular}

\subsection{Compatibility Study}

The FT-IR spectra, XRD patterns of MEL, both MEL-loaded NPs formulations, and the used excipients are presented in Figure 3. 

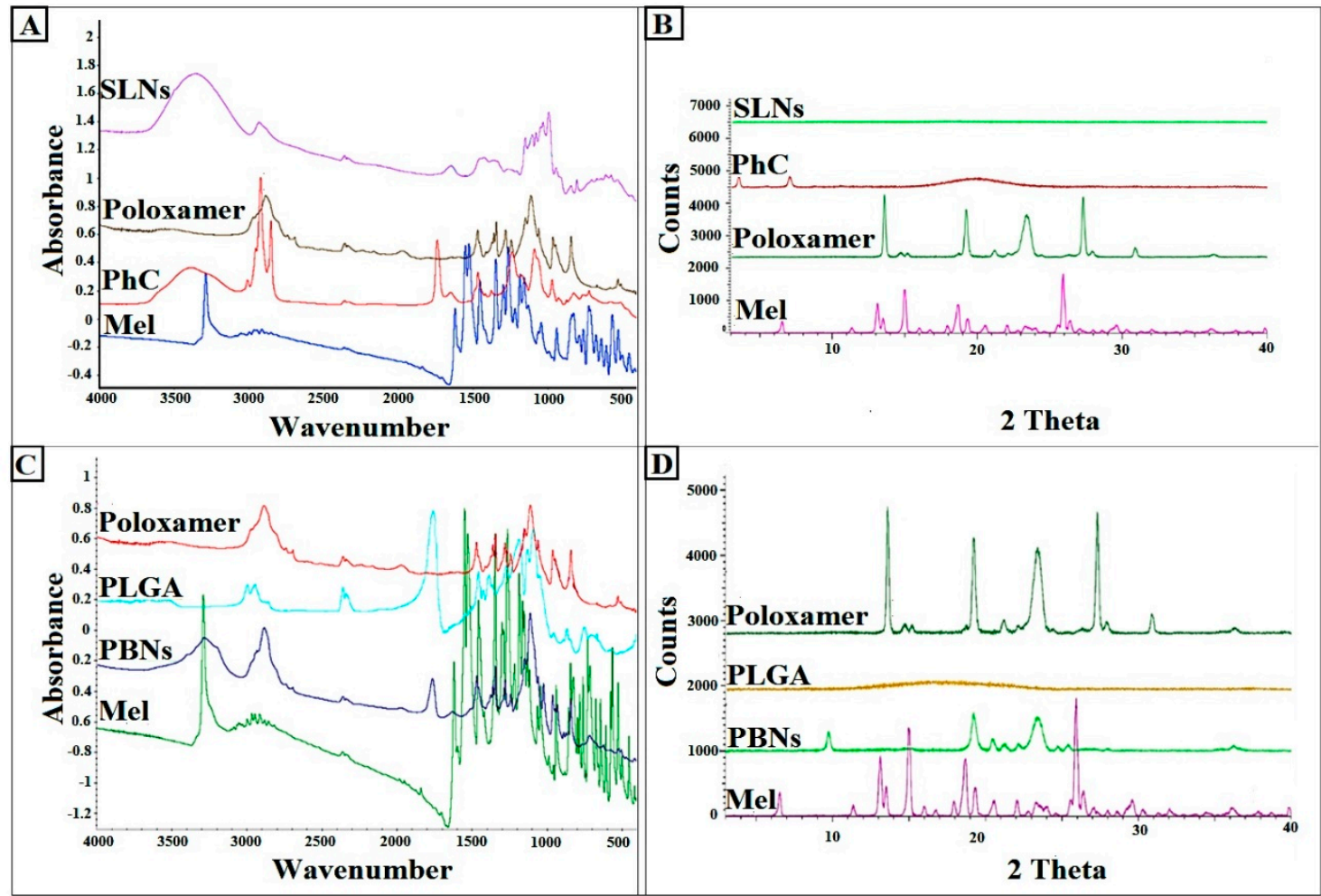

Figure 3. FTIR spectra and XRD patterns of SLNs (A, B) and PBNs (C, D) with their excipients.

\subsection{In Vitro Release Test}

The in vitro dissolution profiles of pure MEL and MEL-loaded NPs were investigated in intranasal-simulated conditions, using simulated nasal electrolytic solution (SNES) medium ( $\mathrm{pH}$ of 5.6) and the results are shown in Figure 4.

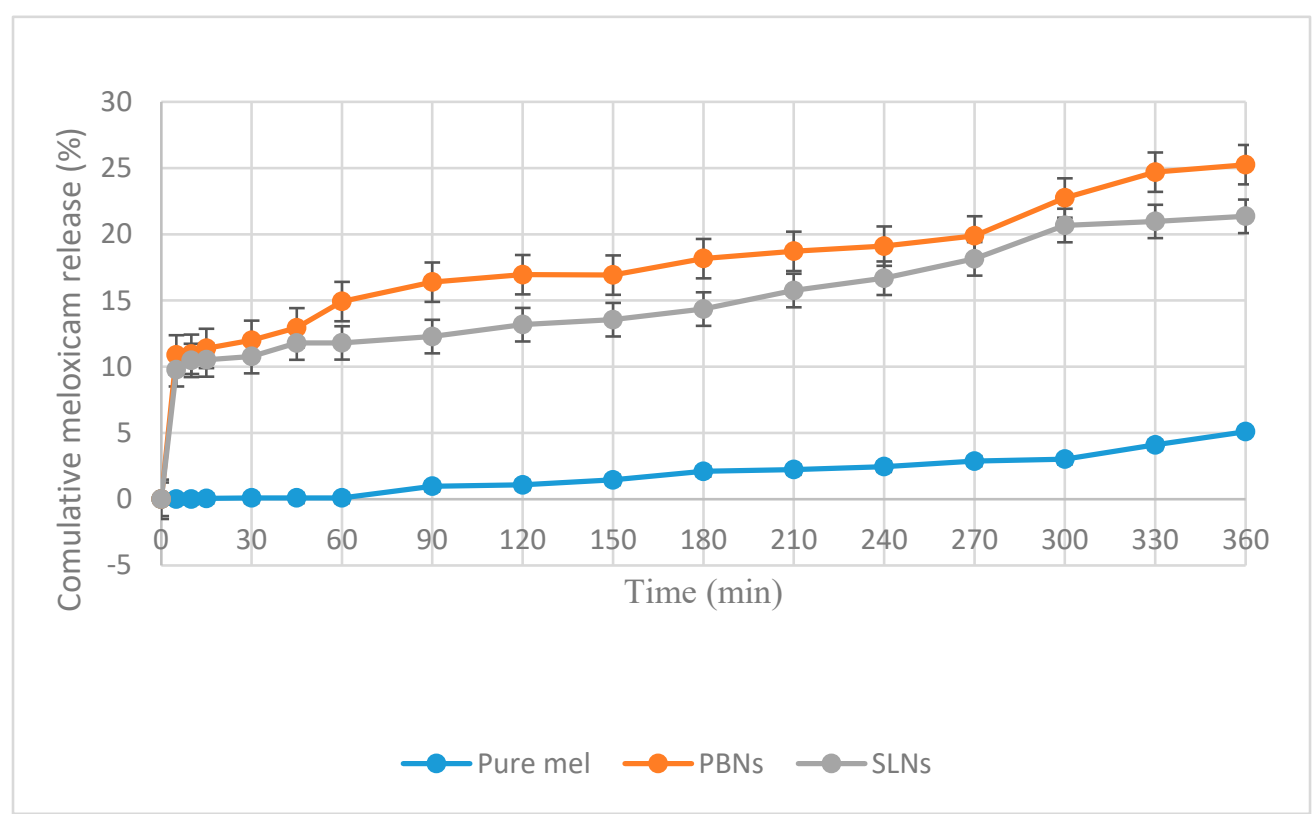

Figure 4. Dissolution behavior of the pure nanoparticles and the prepared nanoparticles.

3.5. In Vito Mucoadhesion Test. 
The mucoadhesion was determined by turbidity analysis method to understand how the NPs will be retained and the results are shown in (Figure 5). Since a strong mucoadhesion suggests a close contact with absorption site, thus ensuring the effective absorption following the nasal administration.

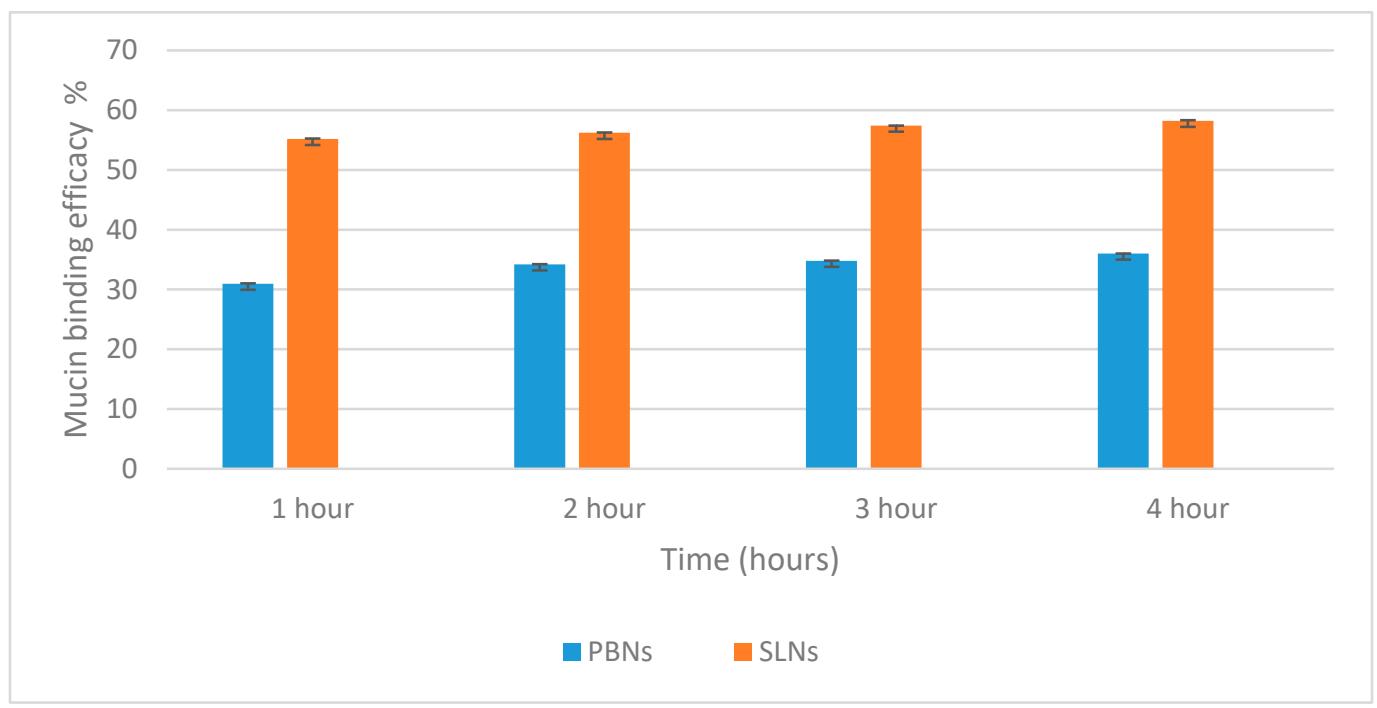

Figure 5. Mucin binding efficacy of the prepared nanoparticles.

\subsection{In Vito Permeation Test}

Permeation test was performed in vitro for pure MEL solution and MEL-NPs, following similar conditions to the nasal delivery route and the result are shown in the following figure (Figure 6).

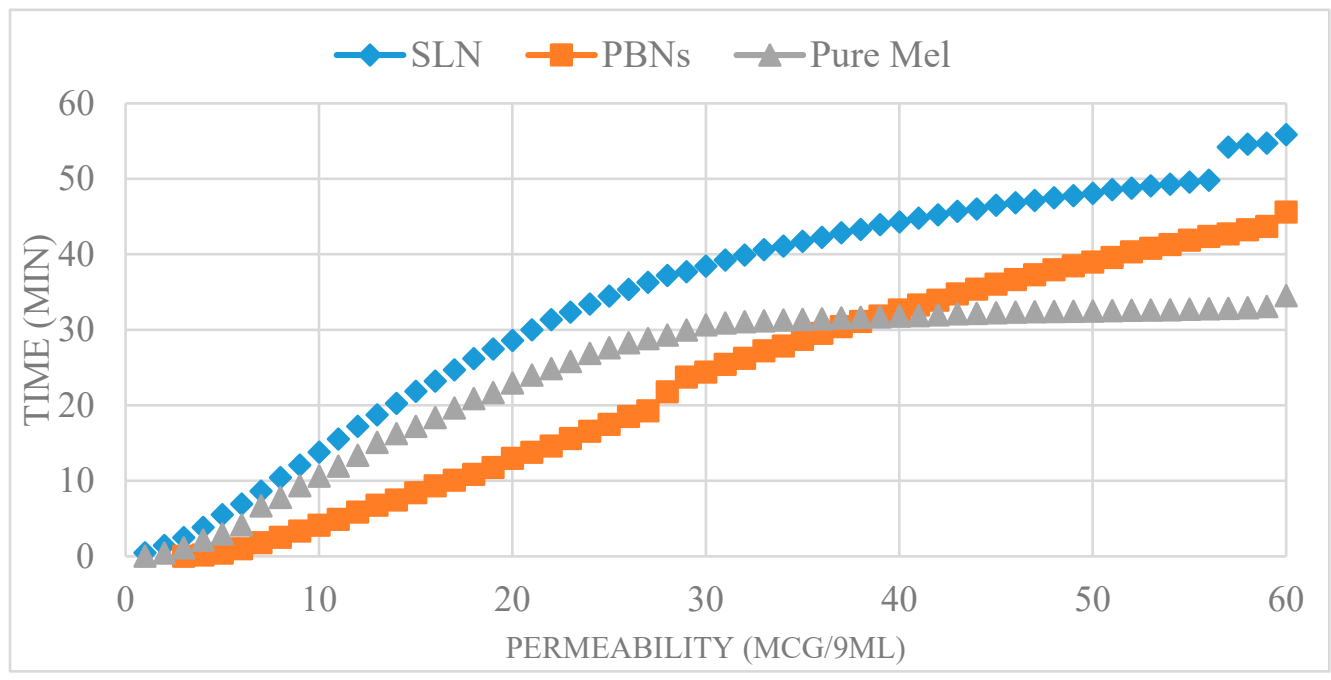

Figure 6. In vitro permeation of the pure meloxicam and the prepared nanoparticles.

\section{Discussion}

Analyzing the results of the risk assessment as a part of QbD and based on the risk priority number RPN demonstrated the most highly influential CPP was sonication time, while the most highly influential CMAs were lipid/polymer type, lipid/polymer concentration, surfactant type, and surfactant concentration as shown in Figure 7. 


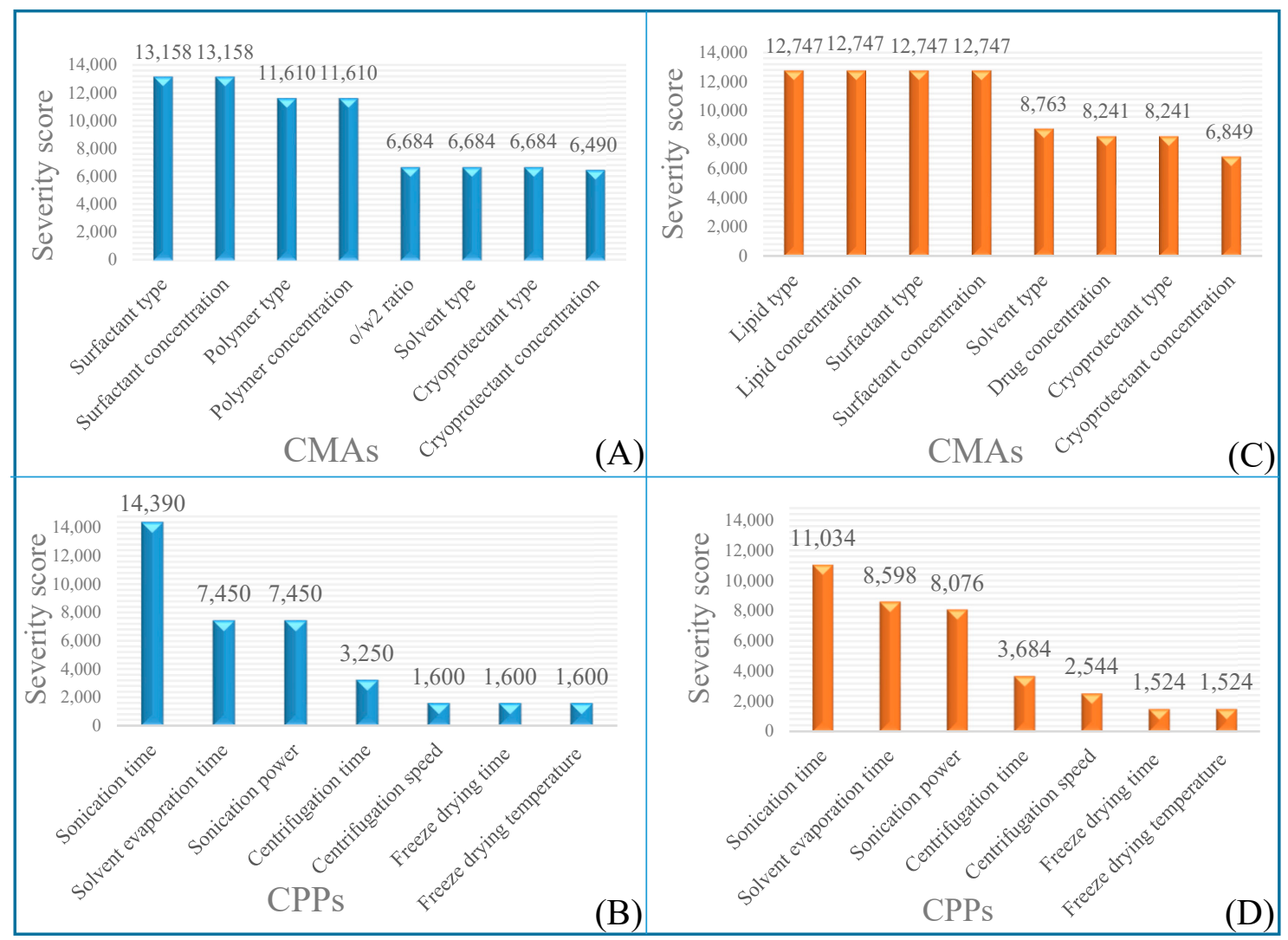

Figure 7. Pareto charts demonstrating the riskiest CMAs and CPPs affecting the formulation of the nanoformulation ranked according to the severity score, of which $(\mathbf{A}, \mathbf{B})$ related to the polymeric nanoparticles, $(\mathbf{C}, \mathbf{D})$ related to the solid lipid nanoparticles. Abbreviation: CMAs-critical material attributes; CPPs-critical process parameters.

Both the NPs types comply with the size requirement of the nasal administration of the drugs for the aim of nose to brain delivery, which is preferred to be up to $200 \mathrm{~nm}[23,24]$.

The zeta potential values obtained for PLGA NPs and SLNs were $-16.2 \pm 1.81$, $-43.65 \pm 1.47 \mathrm{mV}$, respectively, which is logical due to the negative charge of phosphatidylcholine estimated at between -10 and $-30 \mathrm{mV}$ at neutral $\mathrm{pH}$ [25] due to the presence of phosphate and carboxyl groups. In contrast, the negatively charged carboxyl groups on PLGA only are the cause behind the negative charge.

The FTIR spectra of the NPs showed that no changes occurred in the MEL chemical structure and did not present a significant difference in the main functional groups of MEL. The absorption band at $3290 \mathrm{~cm}^{-1}$ correspondings to -NH stretch appears to overlap with the -OH group of phosphatidylcholines, represented at $3200-3400 \mathrm{~cm}^{-1}$. Likewise, the absorption band at $1650 \mathrm{~cm}^{-1}$ matches a slight shift of the $\mathrm{C}=\mathrm{O}$ group. Hence, there is no interaction between MEL and the other SLNs excipients, and they are compatible with each other.

Similarly, absorption peaks of the materials used for polymeric NPs preparation (PLGA, Poloxamer) exhibited compatibility with MEL since the previously mentioned two chemical groups of MEL were maintained the same after PLGA NPs formulations.

The XRD of MEL gave unique fingerprint patterns owing to its crystalline structure. However, both SLNs and PLGA NPs did not show the characteristic fingerprints for the drug in their XRD pattern. The previous confirm that the drugs are present in a nanocrystalline state in the NPs [26]. The previous results are in agreement with the results of FTIR.

Based on Figure 4, it is evident that pure MEL demonstrates a poor solubility $\left(5.10 \pm 0.9 \mu \mathrm{g} / \mathrm{mL}\right.$, over $360 \mathrm{~min}$, at $\left.35^{\circ} \mathrm{C}\right)$ due to the chemical structure it has, and the weak acidic character resulted in this medium $(\mathrm{pKa}=3.43)$ [27]. Fabrication of MEL in nanoformulations showed a significant increase in the dissolution rate than that of pure 
MEL (approximately 4-5 times higher); this goes in line with the results previously reported by Katona et al. and might be due to the nano-size and the increased specific surface area that the NPs have [28].

The release behavior from the NPs showed a sustained release pattern starting by a mild initial burst release during the first hour, where $12.94 \pm 0.86 \%, 11.79 \pm 0.74$ of MEL was released from the PLGA NPs and SLNs, respectively, which has been frequently reported for polymeric NPs $[29,30]$ and SLNs $[13,18]$. A possible explanation for that could be the presence of the drug molecules adsorbing on the NPs surface, in addition to the drug molecules that exist close to the surface having weak interactions with the NPs system. A slow-release profile until $6 \mathrm{~h}$ was then noticed, where only $25.26 \pm 2.39 \%$, $21.37 \pm 1.47$ of cumulative MEL release was observed for PLGA NPs and SLNs, respectively as the encapsulated drug slowly diffused through the NPs core [18]. The previous results point out that most of the drug remained in the NPs after their contact with the nasal mimetic conditions and can release inside the targeted position.

The mucoadhesive strength was detected by calculating the binding efficiency of mucin to PLGA NPs, and SLNs, which were $36.55 \%, 57.59 \%$, respectively, by the end of the experiment, as Figure 5 represents. Since mucin is a highly glycosylated and negatively charged protein, the negatively charged SLNs showed a modest affinity driving, especially by electrostatic interactions between mucin and SLNs. Since SLNs are more negatively charged, the electrostatic interactions between them and mucin will be higher than those with PLGA NPs. This observation is in close agreement with previous studies [31,32].

A significant enhancement of MEL permeability through the semipermeable membrane was achieved when formulating MEL in NPs compared to the pure MEL solution. This could be due to the nanoscale size of the prepared nanosystems, which have the best nasal permeation properties, as previously reported by Gänger et al. [23]. Moreover, the spherical and smooth surface of both NPs, as confirmed by SEM images, leads to the least friction with the membrane surface compared to the needle-shape particles [33]. Stabilizing these NPs using poloxamer, a permeation enhancer, further improves their permeation properties [34] by inhibiting the efflux pumps and lowering the membrane fluidity when it is used in vivo [35].

SLNs showed superior permeability over PLGA NPs, which might be explained by the lipophilic properties of these lipid-based nanosystems [36], which exceed those of PLGA NPs [33].

\section{Conclusions}

The present research work put forward solid lipid nanoparticulate (SLNs) and polymeric based nanoparticle PBNs for the nasal delivery of meloxicam with the purpose of brain delivery. QbD concept was employed to analyze the previous research efforts to define the critical process parameters and the critical material attribute.

All the measurements were found to be in an acceptable range. Spherical nanoparticles were obtained for both SLNs and PBNs with a diameter of 142.06, $94.76 \mathrm{~nm}$, and a ZP of $-16.2,-43.65$, respectively. The resulted nanoparticle showed good compatibility with used materials based on FTIR and XRD measurements. Higher entrapment efficacy and drug load were noticed with SLNs $(87.26 \%, 2.64 \%$, respectively). Better in vitro drug release, permeation and mucoadhesion accomplished the formulation of meloxicam in SLNs more than PBNs. However, ex-vivo data is still needed to investigate cell viability, permeability, and cytotoxicity. Then, in vivo measurements are critical to detect brain concentration and distribution in between brain different parts evaluating the risk/benefit ratio.

Author Contributions: Conceptualization, H.A. and I.C.; methodology, H.A., software: H.A.; validation, H.A formal analysis, H.A. investigation, H.A.; resources, H.A.; data curation, H.A; writing- 
original draft preparation, H.A.; writing - review and editing, H.A., I.C.; visualization, I.C.; supervision, I.C.; project administration I.C. All authors have read and agreed to the published version of the manuscript.

Funding: This research received no external funding.

Institutional Review Board Statement: Not applicable.

Informed Consent Statement: Not applicable.

Data Availability Statement: The data presented in this study are available on request from the corresponding author.

Acknowledgments: The authors want to express their acknowledgement to the supporters. This study was supported by the Ministry of Human Capacities, Hungary (Grant 20391-3/2018/FEKUSTRAT) and by the National Research, Development and Innovation Office, Hungary (GINOP 2.3.215-2016-00060) and (GINOP 2.3.4-15-2020-00006) projects.

Conflicts of Interest: The authors declare no conflict of interest.

\section{Abbreviations}

The following abbreviations are used in this manuscript:

$\begin{array}{ll}\text { BBB } & \text { blood-brain barrier } \\ \text { NSAIDs } & \text { non-steroidal anti-inflammatory drugs } \\ \text { QbD } & \text { quality by design } \\ \text { RA } & \text { risk assessment } \\ \text { Mel } & \text { Meloxicam } \\ \text { SLNs } & \text { solid lipid nanoparticles } \\ \text { PLGA } & \text { Poly (lactide-co-glycolid)e acid } \\ \text { PBNs } & \text { Polymer-based nanoparticles } \\ \text { NPs } & \text { Nanoparticles } \\ \text { EE } & \text { encapsulation efficacy } \\ \text { DL } & \text { Drug load } \\ \text { ZP } & \text { zeta potential } \\ \text { FTIR } & \text { Fourier-transform infrared spectroscopy } \\ \text { XRD } & \text { X-ray powder diffraction } \\ \text { CQAs } & \text { critical quality attributes } \\ \text { CMAs } & \text { critical material attributes } \\ \text { QTPPs } & \text { quality target product profile } \\ \text { CPPs } & \text { critical process parameters }\end{array}$

\section{References}

1. Zhu, Y.; Liu, C.; Pang, Z. Dendrimer-Based Drug Delivery Systems for Brain Targeting. Biomolecules 2019, 9, 790.

2. Mistry, A.; Stolnik, S.; Illum, L. Nanoparticles for direct nose-to-brain delivery of drugs. Int. J. Pharm. 2009, 379, $146-157$.

3. Patel, M.; Souto, E.B.; Singh, K.K. Advances in brain drug targeting and delivery: Limitations and challenges of solid lipid nanoparticles. Expert Opin. Drug Deliv. 2013, 10, 889-905.

4. Pardeshi, C.V.; Belgamwar, V.S. Direct nose to brain drug delivery via integrated nerve pathways bypassing the blood-brain barrier: An excellent platform for brain targeting. Expert Opin. Drug Deliv. 2013, 10, 957-972.

5. Imbimbo, B.; Solfrizzi, V.; Panza, F. Are NSAIDs useful to treat Alzheimer's disease or mild cognitive impairment? Front. Aging Neurosci. 2010, 2, 19.

6. Ah, Y.-C.; Choi, J.K.; Choi, Y.K.; Ki, H.M.; Bae, J.H. A novel transdermal patch incorporating meloxicam: In vitro and in vivo characterization. Int. J. Pharm. 2010, 385, 12-19.

7. Ianiski, F.R.; Alves, C.B.; Ferreira, C.F.; Rech, V.C.; Savegnago, L.; Wilhelm, E.A.; Luchese, C. Meloxicam-loaded nanocapsules as an alternative to improve memory decline in an Alzheimer's disease model in mice: Involvement of Na+, K+-ATPase. Metab. Brain Dis. 2016, 31, 793-802.

8. Ianiski, F.R.; Alves, C.B.; Souza, A.C.G.; Pinton, S.; Roman, S.S.; Rhoden, C.R.; Alves, M.P.; Luchese, C. Protective effect of meloxicam-loaded nanocapsules against amyloid- $\beta$ peptide-induced damage in mice. Behav. Brain Res. 2012, 230, $100-107$.

9. Goverdhan, P.; Sravanthi, A.; Mamatha, T. Neuroprotective effects of meloxicam and selegiline in scopolamine-induced cognitive impairment and oxidative stress. Int. J. Alzheimer's Dis. 2012, 2012, 974013. 
10. Nikvsarkar, M.; Banerjee, A.; Shah, D.; Trivedi, J.; Patel, M.; Cherian, B.; Padh, H. Reduction in aluminum induced oxidative stress by meloxicam in rat brain. Iran. Biomed. J. 2006, 10, 151-155.

11. Badran, M.M.; Taha, E.I.; Tayel, M.M.; Al-Suwayeh, S.A. Ultra-fine self nanoemulsifying drug delivery system for transdermal delivery of meloxicam: Dependency on the type of surfactants. J. Mol. Liquids 2014, 190, 16-22.

12. Sharma, D.; Maheshwari, D.; Philip, G.; Rana, R.; Bhatia, S.; Singh, M.; Gabrani, R.; Sharma, S.K.; Ali, J.; Sharma, R.K.; et al. Formulation and optimization of polymeric nanoparticles for intranasal delivery of lorazepam using Box-Behnken design: In vitro and in vivo evaluation. BioMed Res. Int. 2014, 2014, 156010.

13. Singh, A.P.; Saraf, S.K.; Saraf, S.A. SLN approach for nose-to-brain delivery of alprazolam. Drug Deliv. Transl. Res. 2012, 2, 498507.

14. Akel, H.; Ismail, R.; Csóka, I. Progress and perspectives of brain-targeting lipid-based nanosystems via the nasal route in Alzheimer's disease. Eur. J. Pharm. Biopharm. 2020, 148, 38-53.

15. Pallagi, E.; Ismail, R.; Paal, T.L.; Csóka, I. Initial risk assessment as part of the quality by design in peptide drug containing formulation development. Eur. J. Pharm. Sci. 2018, 122, 160-169.

16. Abou Youssef, N.A.H., Kassem, A.A., Farid, R.M., Ismail, F.A., Magda Abd Elsamea, E.M., Boraie, N.A., A novel nasal almotriptan loaded solid lipid nanoparticles in mucoadhesive in situ gel formulation for brain targeting: Preparation, characterization and in vivo evaluation. Int. J. Pharm. 2018 548, 609-624.

17. Ismail, R.; Sovány, T.; Gácsi, A.; Ambrus, R.; Katona, G.; Imre, N.; Csóka, I. Synthesis and Statistical Optimization of Poly (LacticCo-Glycolic Acid) Nanoparticles Encapsulating GLP1 Analog Designed for Oral Delivery. Pharm. Res. 2019, $36,99$.

18. Yasir, M.; Sara, U.V.S.; Chauhan, I.; Gaur, P.K.; Singh, A.P.; Puri, D.; Ameeduzzafar. Solid lipid nanoparticles for nose to brain delivery of donepezil: Formulation, optimization by Box-Behnken design, in vitro and in vivo evaluation. Artif. Cells Nanomed. Biotechnol. 2018, 46, 1838-1851.

19. Joshi, A.S.; Patel, H.S.; Belgamwar, V.S.; Agrawal, A.; Tekade, A.R. Solid lipid nanoparticles of ondansetron HCl for intranasal delivery: Development, optimization and evaluation. J. Mater. Sci. Mater. Med. 2012, 23, 2163-2175.

20. Dalpiaz, A.; Ferraro, L.; Perrone, D.; Leo, E.; Iannuccelli, V.; Pavan, B.; Paganetto, G.; Beggiato, S.; Scalia, S. Brain uptake of a Zidovudine prodrug after nasal administration of solid lipid microparticles. Mol. Pharm. 2014, 11, 1550-1561.

21. Makled, S.; Nafee, N.; Boraie, N. Nebulized solid lipid nanoparticles for the potential treatment of pulmonary hypertension via targeted delivery of phosphodiesterase-5-inhibitor. Int. J. Pharm. 2017, 517, 312-321.

22. Dyawanapelly, S.; Koli, U.; Dharamdasani, V.; Jain, R.; Dandekar, P. Improved mucoadhesion and cell uptake of chitosan and chitosan oligosaccharide surface-modified polymer nanoparticles for mucosal delivery of proteins. Drug Deliv. Transl. Res. 2016, 6, 365-379.

23. Gänger, S.; Schindowski, K. Tailoring Formulations for Intranasal Nose-to-Brain Delivery: A Review on Architecture, PhysicoChemical Characteristics and Mucociliary Clearance of the Nasal Olfactory Mucosa. Pharmaceutics 2018, 10, 116.

24. Masserini, M. Nanoparticles for brain drug delivery. ISRN Biochem. 2013, 2013.

25. Zhou, Y.; Raphael, R.M. Solution pH alters mechanical and electrical properties of phosphatidylcholine membranes: Relation between interfacial electrostatics, intramembrane potential, and bending elasticity. Biophys. J. 2007, 92, $2451-2462$.

26. Sipos, B.; Szabó-Révész, P.; Csóka, I.; Pallagi, E.; Dobó, D.G.; Bélteky, P.; Kónya, Z.; Deák, Á.; Janovák, L.; Katona, G. Quality by Design Based Formulation Study of Meloxicam-Loaded Polymeric Micelles for Intranasal Administration. Pharmaceutics 2020, 12, 697.

27. Avdeef, A. Permeability-PAMPA In Absorption and Drug Development; John Wiley \& Sons, Inc.: Hoboken, NJ, USA, 2012.

28. Katona, G.; Balogh, G.T.; Dargó, G.; Gáspár, R.; Márki, Á.; Ducza, E.; Sztojkov-Ivanov, A.; Tömösi, F.; Kecskeméti, G.; Janáky, T.; Kiss, T. Development of meloxicam-human serum albumin nanoparticles for nose-to-brain delivery via application of a quality by design approach. Pharmaceutics 2020, 12, 97.

29. Araújo, F.; Shrestha, N.; Shahbazi, M.A.; Fonte, P.; Mäkilä, E.M.; Salonen, J.J.; Hirvonen, J.T.; Granja, P.L.; Santos, H.A.; Sarmento, B. The impact of nanoparticles on the mucosal translocation and transport of GLP-1 across the intestinal epithelium. Biomaterials 2014, 35, 9199-9207.

30. Dinarvand, R.; Sepehri, N.; Manoochehri, S.; Rouhani, H.; Atyabi, F. Polylactide-co-glycolide nanoparticles for controlled delivery of anticancer agents. Int. J. Nanomed. 2011, 6, 877.

31. Luo, Y.; Teng, Z.; Li, Y.; Wang, Q. Solid lipid nanoparticles for oral drug delivery: Chitosan coating improves stability, controlled delivery, mucoadhesion and cellular uptake. Carbohydr. Polym. 2015, 122, 221-229.

32. Aderibigbe, B.A.; Naki, T. Chitosan-based nanocarriers for nose to brain delivery. Appl. Sci. 2019, 9, 2219.

33. Ismail, R.; Bocsik, A.; Katona, G.; Gróf, I.; Deli, M.A.; Csóka, I. Encapsulation in Polymeric Nanoparticles Enhances the Enzymatic Stability and the Permeability of the GLP-1 Analog, Liraglutide, Across a Culture Model of Intestinal Permeability. Pharmaceutics 2019, 11, 599.

34. Bahadur, S.; Pathak, K. Physicochemical and physiological considerations for efficient nose-to-brain targeting. Expert Opin. Drug Deliv. 2012, 9, 19-31.

35. Fischer, S.M.; Brandl, M.; Fricker, G. Effect of the non-ionic surfactant Poloxamer 188 on passive permeability of poorly soluble drugs across Caco-2 cell monolayers. Eur. J. Pharm. Biopharm. 2011, 79, 416-422.

36. Esim, O.; Savaser, A.; Ozkan, C.K.; Oztuna, A.; Goksel, B.A.; Ozler, M.; Tas, C.; Ozkan, Y. Nose to brain delivery of eletriptan hydrobromide nanoparticles: Preparation, in vitro/in vivo evaluation and effect on trigeminal activation. J. Drug Deliv. Sci. Technol. 2020, 59, 101919. 